\title{
Gold in Silicon Solar Cells
}

\section{POWER SUPPLY SYSTEMS FOR SATELLITES}

Thousands of the silicon solar cells used to power vehicles in space incorporate gold current collectors on their front faces, and also gold areas on their back faces to which electrical contact is made by soldering. Gold is used because of its high electrical conductivity, excellent resistance to corrosion and good solderability.

Every piece of equipment operating in the space environment needs a power supply and the type of power unit varies with the type of mission. Simple probes launched by rockets depend on batteries during the short ballistic flights which end when the probes fall back into the atmosphere. Manned missions have depended so far on batteries and on fuel cells, both of which can operate for several days or weeks during journeys to the moon or during prolonged orbiting of the earth. However, fuel cells and batteries are unsuitable for longer operation in space. The limiting factor is the amount of fuel which it is possible to carry aboard the spacecraft to sustain the electrochemical reactions of such devices.

There are two types of power supply for extended use in space-heat produced by the decay of a radioactive isotope, and the solar cell. The former is limited by the shielding which is required (at least while men have to handle them), since this increases the weight to be launched into space. However, arrays of instruments left on the moon by the Apollo astronauts are powered by electricity produced thermoelectrically from the heat of radioactive decay of an isotope. Such a power source is expected to last for at least a year.

The solar cell is at present the best power source for realiy long operation over a number of years and is used in unmanned satellites and deep-space probes of all kinds. For example, all telecommunications satellites depend for their operation on silicon solar cells. So do meteorological satellites, experimental satellites, and the Mars and Venus probes launched

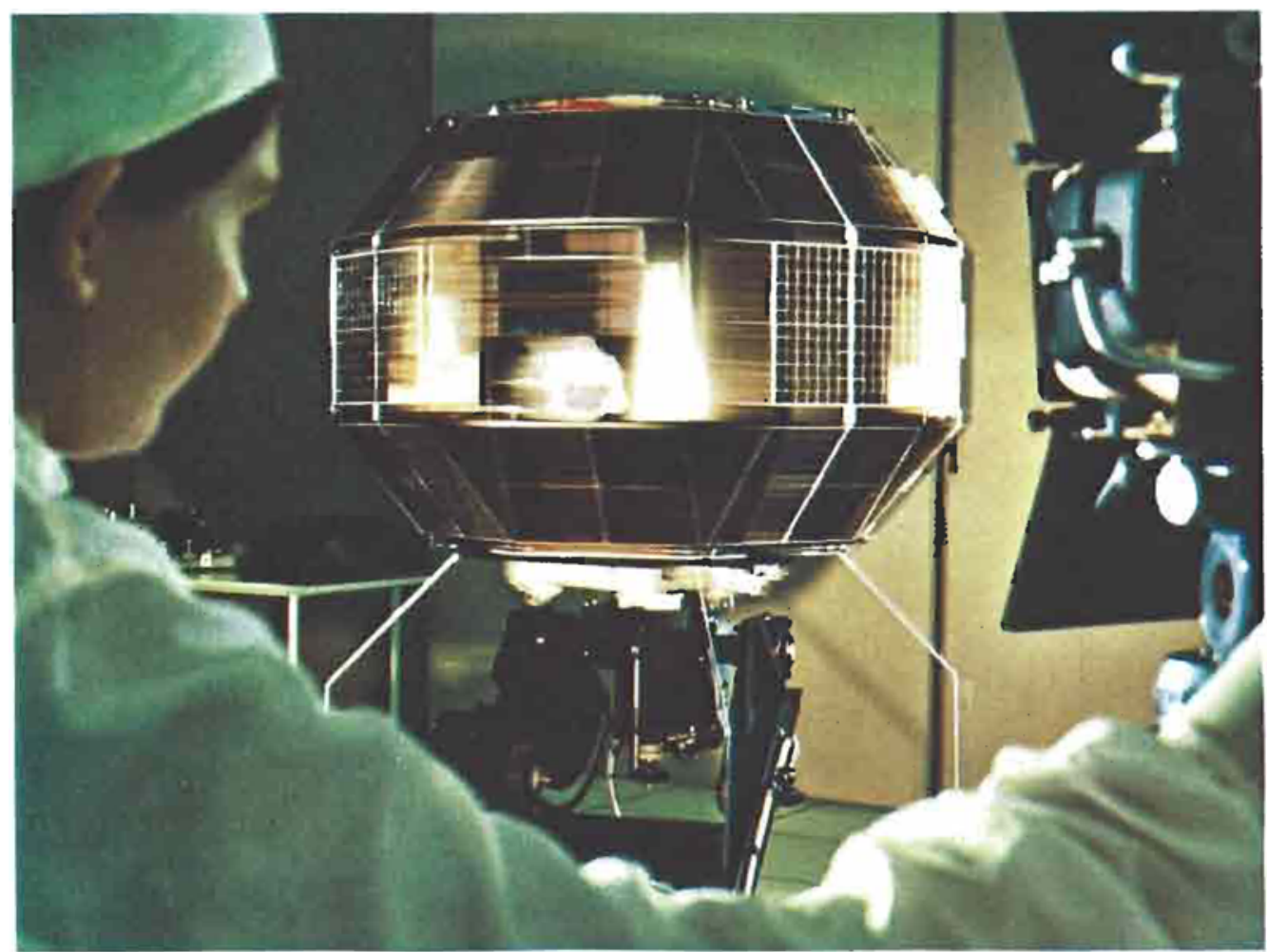

Fig. 1. The solar cells of the British experimental satellite Prospero under test in the Marconi laboratories at Portsmouth. The size of the numerous cells is apparent. Prospero, launched in Oetober 1971, is the first British satellite to be launched by a British rocket, the Black Arrow 


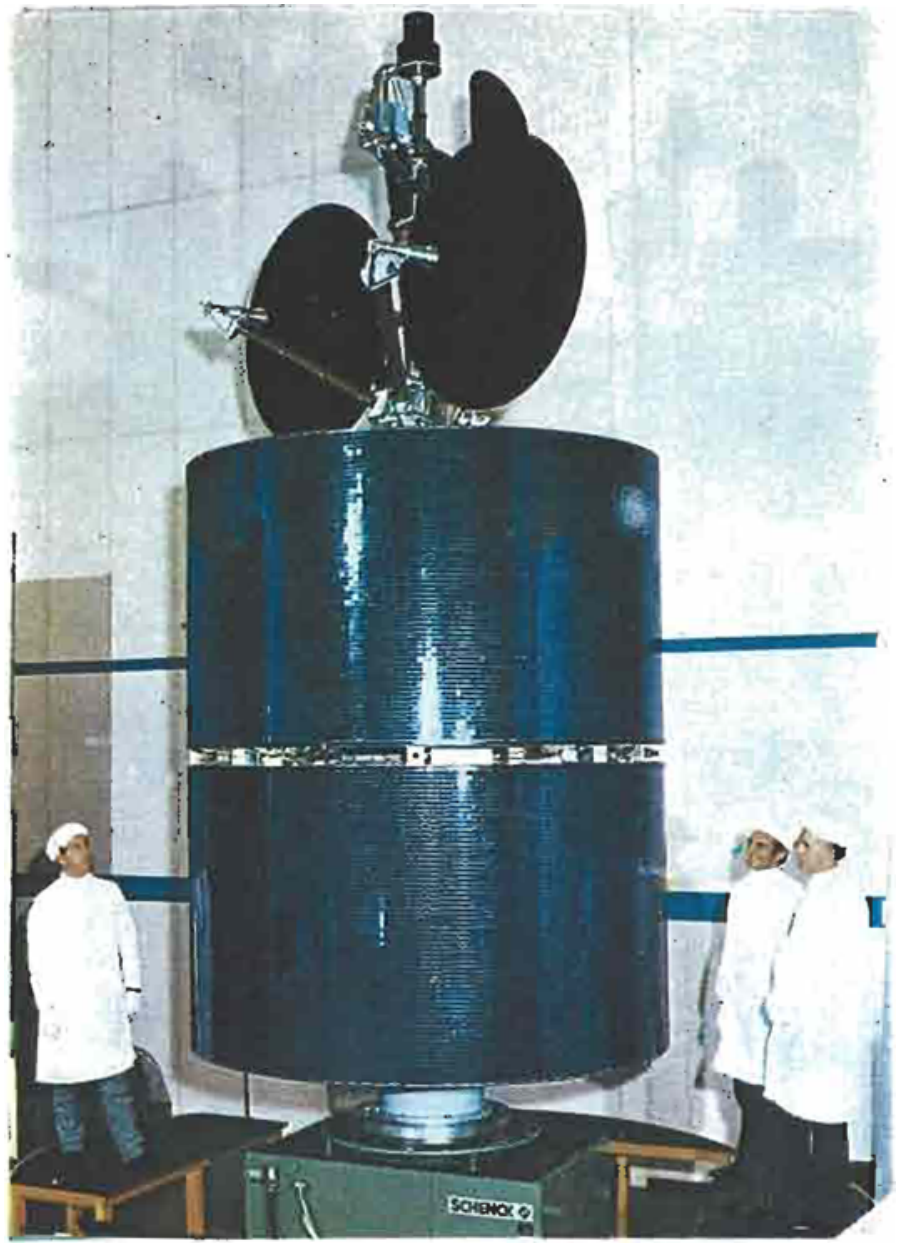

by both the United States and the Soviet Union. The banks of solar cells have become familiar features of illustrations of such vehicles. The solar panels either cover the bodies of the satellites or form paddle arrays on booms attached to the bodies of the deep-space probes.

Solar cells depend for their operation on the photovoltaic principle. Sunlight striking the surface of a solar cell generates a small current through an external circuit connecting the silicon $p$ and $n$ regions. These regions are formed by doping each pure silicon wafer with traces of boron and arsenic respectively. When photons of solar light energy fall on the face of the solar cell they jolt electrons out of their fixed positions in the doped silicon and thereby generate free electrons and "holes". Electrons and holes migrate to redress the balance and in so doing produce a small electric current. In theory 45 per cent of the total energy in the solar spectrum is capable of being tapped by a photoelectric solar battery but in practice a smaller proportion of the energy falling on the face of a solar cell is converted into useful current.

As might be expected, the power produced at a single solar cell is minute, amounting to only a fraction of a watt per square centimetre of surface
Fig. 2. The InteIsat IV telecommunications satellite, the most advanced in service, has the capacity to relay twelve television channels and 9,000 telephone circuits througlıout its designed seven-year life. Power for these relays is provided by over 40,000 silicon solar cells, which together generate 569 watts dropping to 460 watts at a constant 23.8 volts. Each cell incorporates a gold current collector grid on its front face and a gold contact area on its reverse

exposed to the sun. Therefore large numbers of cells are connected in series-parallel arrays to give sufficient power to operate the on-board systems of spacecraft. In the case of attitude-stabilised spacecraft it is necessary for the cells to point in only one direction to receive the sun's rays and flat arrays of cells are sufficient. Where the vehicle is spin-stabilised it is necessary for some cells to be pointing at the sun at all times as the vehicle rotates. This has led to the development of the typical barrelshaped satellites which always have a steady proportion of their cells receiving solar energy during rotation.

Each facet of an experimental satellite typically has well over a hundred solar cells to power the electronic circuits within. Such a satellite is shown in Fig. 1. Some large cylindrical satellites have arrays with many thousands of cells. For example, the first of the Intelsat IV telecommunications satellites, shown in Fig. 2, has two main cylindrical arrays comprising 42,240 cells, which together generate 569 watts at the beginning of the active life of the satellite. The power is expected to decline to 460 watts by the end of the planned seven-year life of this synchronous satellite. This decline will be due mainly to damage to the faces of the cells by micrometeorites during service-not to defects in the silicon solar cells.

The Intelsat IV design is the most advanced satellite built for the International Telecommunications Satellite Consortium. Four of the type are planned. The Hughes Aircraft Co. of the U.S.A. is the main contractor but the British Aircraft Corporation is responsible for the construction of the twin solar panels. Ferranti Limited made the cells for these panels on the first of the series to be launched. This satellite has been in service since March 1971. The second has also been launched and is working satisfactorily. 
Fig. 3. Silicon solar cells manufaetured by Ferranti Limited at Oldham, Lancashire. The front face gold grids each consist of a $1 \mathrm{~mm}$ gold line along the top cdge of the cell with $0.2 \mathrm{~mm}$ gold current collector lines extend. ing to within $0.25 \mathrm{~mm}$ of the bottom edge. The reverse face gold area is surrounded by a 1 mm frame to prevent splashing during soldering

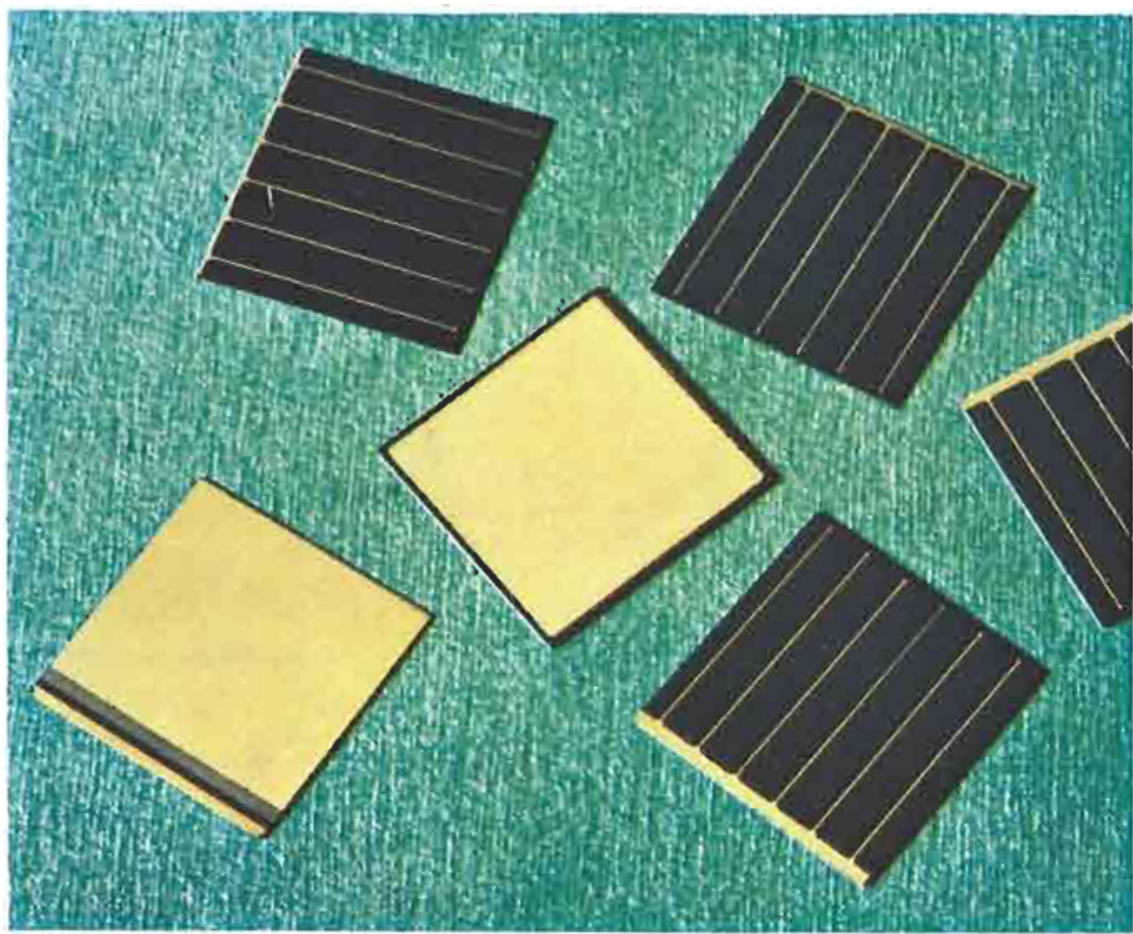

Each of the Ferranti silicon solar cells incorporates a contact structure, deposited electrochemically, of copper, nickel and gold on both its front and back faces as shown in Fig. 3. The front face of each cell receives the solar energy and to increase the efficiency of electron collection from this face a grid of fine gold lines is superimposed on the silicon. Gold is used because of its high electrical conductivity, together with its resistance to corrosion on earth during storage before flight. The gold grid consists of a $1 \mathrm{~mm}$ wide gold line along one edge of the $2 \mathrm{~cm}$ square cell. Six gold lines $0.2 \mathrm{~mm}$ wide extend from this line across the face of the cell to within $0.25 \mathrm{~mm}$ of the opposite edge. The gap prevents possible contact to the next cell below in the array.

Each cell is soldered into position in its array to make good electrical contact to the power circuit. The attachment is made to the large gold area on the back of the cell. Usually there is a $1 \mathrm{~mm}$ "picture frame" around the gold area to prevent splashing of solder during fabrication; such splashing might otherwise cause unwanted electrical connections to adjacent cells. Gold is used to assist solderability and it also inhibits oxidation of substrate copper during storage.

Ferranti has found that gold is superior to the materials used by other manufacturers for these two purposes. The same type of cell used in Intelsat IV has been supplied for the British experimental Prospero satellite. Cells for this vehicle have been assembled into panels for Marconi by Ernest Turner Electrical Instruments Ltd. Prospero (known as X3 before launch) was launched by the British Black Arrow rocket in October 1971. At the time of writing Ferranti have manufactured 140,000 of these cells for various types of satellite and are to supply cells for Britain's X4 satellite, the next in the series.

F. J. S.

\section{A Proposed New High-pressure Calibration Scale}

Geophysical research is currently being undertaken at pressure levels that must be estimated rather than measured and where the possibilities for error are very considerable. Practical measuring techniques are needed, therefore, which provide a pressure calibration curve that can be extrapolated with confidence from the lower accurately known levels up to pressures of the order of $200 \mathrm{kbar}$. The curve obtained by plotting the melting point of gold as a function of pressure can satisfy this requirement. It increases linearly from $1063^{\circ} \mathrm{C}$ at one atmosphere to $1404^{\circ} \mathrm{C}$ at
65 kbar and if extrapolated to 200 kbar a melting point of $1988^{\circ} \mathrm{C}$ would be expected. J. Akella and G. C. Kennedy of the University of California (7. Geophys. Res., 1971, 76, (20), 4969) have recently proposed that this curve should be used as a primary measuring standard between 100 and $200 \mathrm{kbar}$ and in the temperature interval 1600 to $2000^{\circ} \mathrm{C}$. Over this range, pressure differences of $0.5 \mathrm{kbar}$ correspond to temperature differences of 1 to $2 \mathrm{deg} C$, which should be measureable with a suitable high temperature thermocouple. 